\section{Pdife
DTCF
DERGiSi
JOURAL}

Makale Bilgisi

Makale türü: Arasttırma makalesi Gönderildiği tarih: 18 Kasım 2021 Kabul edildiği tarih: 5 Aralık 2021 Yayınlanma tarihi: 28 Aralık 2021

Article Info

Type of article: Research article Date submitted: 18 November 2021

Date accepted: 5 December 2021

Date published: 28 December 2021

\section{Anahtar sözcükler}

Yunus Emre; Yunus Emre Divani; Dil; Söz

Keywords

Yunus Emre; the Diwan of Yunus

Emre; Language; Word

\title{
YUNUS'UN SÖZÜ'
}

THE “WORD” OF YUNUS

\section{Bilal ÇAKICI}

Doç. Dr., Ankara Üniversitesi, Dil ve Tarih-Coğrafya Fakültesi, Türk Dili ve Edebiyatı Bölümü, Eski Türk Edebiyatı Anabilim Dalı, cakicib@ankara.edu.tr

\section{$\ddot{O} z$}

Yunus Emre, Anadolu'da Türk yazı dilinin olușmasında çok önemli bir yeri olan, şiirlerindeki evrensel mesajlarıla Türk edebiyatının en çok bilinen ve okunan şairlerindendir. Bize biraktığı Divan ve Risaletü'n-Nushiyye, herkesin kendi düşüncesine göre yararlandiğı ve sorularina cevap bulduğu metinlerdir. Bu yazıda Yunus'un "söz hakkındaki düşünceleri, sözün kaynağı, nasıl söylenmesi gerektiği, sözde, sözü söyleyende ve dinleyende aranan özellikler, sözün tesiri, gücü" gibi konular, şiirlerinden örneklerle değerlendirilecektir.

\begin{abstract}
Yunus Emre, is one of the most well-kown and most-read poets of Turkish literature who played a key role in the formation of Turkish written language and conveyed universal messages to humanity with his poems. His Diwan and Risaletü'n-Nushiyye are works which everyone can benefit from in his/her own way; works which offer answers to everyone's questions. This paper deals with issues such as Yunus' "thoughts about words, the source of words, the way they must be said, characteristics to be sought in a word as well as in the one who says it and listens to it, the effect and power of words" and discusses these based on examples from his poems.
\end{abstract}

\section{Giriş}

İncil'de "Her şeyin başlangıcından önce Tanrısal Söz vardı. Tanrısal Söz Tanri'yla birlikteydi ve Tanrı neyse Tanrısal Söz de O'ydu.” (Íncil, 1998, s.181) ifadeleriyle sözün var edici, yaratıcı gücüne dikkat çekilmiş; İslam inancına göre ise var oluş Tanrı'nın bir "kün/ol" demesi ile (Kur'ân-ı Kerîm, 2004, s.435), yani tek bir sözle başlamıştır. Sözün ilahi veya gizemli bir yönü olduğuna inanılmış; birçok filozof, sözün bizzat "Allah” olduğunu söylemiştir. Yine güzel söz; "kökü yerde sabit, dallar1 gökte olan güzel bir ağaca; kötü söz ise kökü yerden sökülmüş, ayakta duramayan bir ağaca" (Kur'ân-ı Kerîm, 2004, s. 244) benzetilmiştir.

$1 \quad 14$ Ekim 2021 tarihinde Ankara Üniversitesi Dil ve Tarih-Coğrafya Fakültesi'nde gerçekleştirilen "Ankara Üniversitesi'nin Kuruluşunun 75. Y1l Dönümünde Dünya İnsanlığ1 İçin Ortak Bir Değer: Yunus Emre ve Bir Medeniyet Dili: Türkçe" adlı Panel'de sunulan konuşma metninin makale formatına dönüştürülmüş biçimidir. 
Dil sisteminin en küçük yapı taşı olarak söz bir yönü lafza, bir yönü manaya açılan bir kapıdır. Her ne kadar Mevlana, "Dilin müşterisi kulaktır ancak." (Karaismailoğlu, 2004, s. 37) dese de dil, harfler aracılığıyla göze, sesler aracılığıyla kulağa hitap eder.

Söz ile ilgili bu değerlendirmelere daha nicelerini eklemek mümkündür. Peki Yunus Emre, bu konuda neler söylemiştir?

Öncelikle şunu belirtmek gerekir ki Yunus Emre'nin çok bilinmesi tesadüf değildir. Yunus bize bir divan ve bir mesnevi dışında bir şey bırakmadı ama onu, temsil ettiği dünyanın ötesine taşıyan ve bu kadar bilinir kılan şey, sözündeki mana ve tesirdir. Divanı, her bir okurun kendi bakış açısına göre cevaplar bulabileceği bir metindir.

Mevlana'nın deyimiyle "Denizi bir testiye döksen, ne kadar alır? Bir günlük k1smet." (Karaismailoğlu, 2004, s. 37) Bu yazıda Yunus'un söz okyanusundan bizim testimizin alabileceği oranda, "dil/söz nedir, hangi ihtiyacı karş1lar, anlaşmak için yeterli midir, söz nasıl söylenmelidir, sözün kaynağ1 nedir, sözü söyleyende ve dinleyende aranan özellikler nelerdir, sözün tesiri ve gücünün sebebi nedir?” gibi soruların cevapları aranacak, böylece Yunus'un "söz"e verdiği değer, "söz"ün mahiyetine dair düşünceleri, Divan'ından hareketle değerlendirilecektir. Çünkü bir şairin/yazarın edebî şahsiyetini ortaya koymak için, edebiyat tarihi kaynaklarındaki birçok veriyi bir arada değerlendirmek çok önemlidir ancak daha da önemlisi bu konuda en muteber bilgilere, eserlerden ve şairin dediklerinden hareketle ulaşılabileceği göz ardı edilmemelidir.

Divan'daki her şeyi bir kenara bıraksanız bile, Yunus Emre'nin "eger maksûd eserse mısra'-1 berceste kâfîdir" kabilinden bir sözü var ki geçen asırda Heidegger’in "Dil varlığın evidir." ya da buradan hareketle "Dil düşüncenin evidir." sözüyle eriştiği seviyeye bizim medeniyetimizde asırlar öncesinden ulaşıldığını göstermesi bakımından üzerinde düşünülmesi gerekir:

Sûret söz kanda buldı kanda sözi iş oldı

Sûrete kendü geldi dil hikmetün yolıdur (Divan 25/3)2

\footnotetext{
$2 \mathrm{Bu}$ yazıda alıntılanan şiirlerden veya beyitlerden sonra yay ayraç içinde yazılan "Divan", aşağıda künyesi verilen eseri, sonraki rakamlar sırasıyla bu yayındaki şiir ve beyit numarasını göstermektedir: Mustafa Tatc1. Yûnus Emre Divânt-Tenkitli Metin (2. Baskı). İstanbul: Milli Eğitim Bakanlığı, 2005.
} 
"Dil hikmetin yoludur." yani dil ile düşünce/felsefe arasındaki ilişkiyi -bu bağlamda Arapçada nutk/mantık kelimelerinin kökteş olduğunu da hatırlamak gerekir- bir serlevha olarak en üst düzeye taşıyan Yunus'un, dilin çeşitli yönlerine ilişkin dile getirdikleri kayda değerdir.

Bu kapsamda aşağıdaki gazelin, Yunus'un sözün/dilin niteliklerini özetlemesi bakımından, en başta zikredilmesi yerinde olacaktır:

Keleci bilen kişinün yüzini ag ide bir söz

Sözi bişürüp diyenün işini sag ide bir söz

Söz ola kese savaşı söz ola bitüre baş1

Söz ola agulu aşı balıla yag ide bir söz

Kelecilerün bişürgil yaramazunı şeşürgil

Sözün usıla düşürgil dimegil çag ide bir söz

Gel ahî iy şehriyâri sözümüzi dinle bâri

Hezâr gevher ü dînârı kara toprag ide bir söz

Kişi bile söz demini dimeye sözün kemini

Bu cihân cehennemini sekiz uçmag ide bir söz

Yüri yüri yolunıla gâfil olma bilünile

Key sakın key dilünile cânına dâg ide bir söz

Yûnus imdi söz yatından söyle sözi gâyetinden

Key sakın o şeh katından seni ırag ide bir söz (Divan 102).

Sözü konu alan bir diğer gazel ise şöyledir:

İy sözlerün aslın bilen gel di bu söz kandan gelür

Söz aslını anlamayan sanur bu söz benden gelür

Söz var k1lur gönüli şâd söz var kılur bilişi yad

Eger horluk eger 'izzet her kişiye sözden gelür

Söz karadan akdan degül yazup okımakdan degül

Bu yüriyen halkdan degül Hâlik âvâzından gelür 
Ne elif okıdum ne cim ne varlıkdandur kelecim

Bilmeye yüz bin müneccim tâli'üm ne 1lduzdan gelür

Evvel gönül levhinde Hak yazmışıdı çün bir varak

Bu şimdi okınan sebak ezel-i âzâldan gelür

Evvel hitâb kılur câna cânı andan gelür tene

Biz âletüz bahâne ayruk ne elümüzden gelür

'Aklumuz ol levhe bakar gizli marazlarum açar

Söz gelür gönlüme akar söz dile ansuzın gelür (Divan 42).

Bu iki gazelden sonra Yunus'un Divan'ına perakende olarak dağıttığı söze dair söz incilerine bakıldığında, başta "sözün kaynağı", "sözün nitelikleri ve gücü", "sözü söyleyen ve dinleyende aranan özellikler" olmak üzere sözün farklı yönlerine dikkat çekildiği görülür.

\section{Önce söz vard1:}

Dahı yir gök yogıdı cümle söz mensûhıdı

‘Âş1klar taparlardı ol bî-nişân Sübhân’a (Divan 320/8).

Gice ile gündüzi gökde yidi yılduzı

Levhde yazılan sözi cümle vücûdda bulduk (Divan 133/4).

beyitleriyle Yunus, daha hiçbir şey yok iken sözün varlığına, levh-i mahfuzda yazılı olan sözün varlığın kaynağı olduğuna işaret etmektedir.

\section{Sözün kaynağ1:}

Önce söz varsa ve söz de Tanrı ise sözün kaynağı da Yunus'u söyleten ve ona söz söyleme kabiliyeti veren de O’dur:

Benüm degül bu keleci varlık senün Yûnus neci

Çün dilüme sensin kadîr sensüz lisân depretmeyem (Divan 183/9).

Düşmânlar eydür bana söz dimek kandan sana

Bana söz dimek kandan benüm üstâdum vardur (Divan 51/3).

Bu söz Yûnus'a kandan kim vire haber cândan

Meger kim ol lutf 1ss1 ana nazar eyledi (Divan 355/10). 
Sözünü kimden aldığını bu beyitlerle ifade eden Yunus, "divan-1 aşkun defterinde" söylenenleri hatırlamakta, sözlerini "aşk âlemi”nden söylemektedir:

Yûnus'a sorarısan bu sözleri kandan alur

Meger ol dîvân-1 'işkun defterinden yâd ider (Divan 67/9).

Yûnus miskîn bu sözi 'sşk ‘âleminden söyler

Dime bilmedin ana kendözünden katarsın (Divan 248/12).

Yunus'a göre gönülde olmayan şey, dile gelmez; bir başka deyişle "aşk ağlatır, dert söyletir:

Çün bülbül ‘âşıkdur güle nazar Hak'dan olur kula

Bir keleci gelmez dile gönüllerde bitmeyince (Divan 325/4).

Dosta 'âş1k olanun güci sözine yiter

Güci sözine yiten sözini dilden kodı (Divan 369/6).

Kişi neyi severise dilinde sözi ol olur

Gensüz söyleyesüm gelür gönlüm alanun sözini (Divan 359/4).

\section{Söz söyleme yeteneği herkese verilmemiştir:}

Yunus, yazımızın başında tamamı verilen "söz" redifli gazelinde sözün savaşları bitirebildiğini, ağızdan çıkan sözün kişinin hayatına mal olabileceğini, sözün zehirli bir yemeği bile tatlandırabileceğini vs. dile getirmişti. Aşağıdaki beyitlerde ise söz söyleme yeteneğinin kişiden kişiye farklılık gösterdiğini, bu özelliğin herkese nasip edilmediğini vurgulamaktadır:

Hücrede vü bucakda Hakk’a lâyık olmadum

Kiminde derd ü firâk kiminde eserlü söz (Divan 106/3).

Agız agızdan kutludur ola ki sözünüz duta

Ben yüz bin kez söylerisem sözüm kulagına girmez (Divan 104/8). 


\section{Sözü söyleyende aranan nitelikler:}

Sözü tesirli kılmanın bir yolu da söylenenin öncelikle hayata tatbik edilmesidir. Sözü söyleyende söylenen şeyden eser olmalıdır, aksi hâlde kişi inandırıcılığını kaybeder. Yaşanmamış bir şeyi söylemek karpuzun ağaçta yetişmesine benzer:

Olmaz sözi dimezem ben ma'rifet ehline Zîrâ disem inanmaz agaçda bitdi karpuz (Divan 106/6).

İş bu sözi eydenden bize nişân gerekdür

Söz muhtasârı budur cânına kıyan gelsün (Divan 237/5).

Yûnus sözün kime dirsin yâ kimün kaygusin yirsin

Nasîhat halka eylersin yâ özün neye tutmazsın (Divan 235/9).

Söz, gücünü söyleyenden alır; söyleyen arif olmalıdır; cahil ne kadar çok konuşursa konuşsun sözleri manasızdır:

Eger güher isterisen hıdmet eyle 'âriflere

Câhil bin söz söyler ise ma'nîde miskâl olmaya (Divan 5/6).

Kişi bildiğini söylemeli, sözünü bilmeli, yerli yerince (hâlin gerektirdiği şekilde) konuşmalı, işittiğini söylemeli, söze söz katmamalıdır:

İ Yûnus sen sözün bilgil

Öz hâlüne nazar kilg1l (Divan 218/6).

Miskîn Yûnus bil sözüni dosta açup şol gözüni

Kang1 burcdan bakarısan ol sultâna güneş gelür (Divan 92/8).

Söyledügün keleciyi işitdügün gibi söyle

Kendözünden zîreklenüp bir kaç söz dahı katmagıl (Divan 159/6). 


\section{Dinleyende aranan özellikler:}

Sözü söyleyen kadar dinleyen de iletissim açısından önemlidir. Dilin müşterisi kulaktır ve müşterisiz meta ise zayidir. Sözden nasibi olmayana, kulağını hakikate kapayanlara söz söylememek gerekir:

Ol kişi kim sagır durur söyleme Hak sözin ana

Ger dir isen zâyi' olur nasîb yokdur sözden ana (Divan 11/6).

İçinde zerre kadar aşk/dert olmayana söylenen sözler "kaya yankısına" benzetilmekte, muhatabını bulmayan sözün boşluğa, boşuna söylendiği dile getirilmektedir. Yine Mevlana'nın deyimiyle, “iştiyak derdini anlatmak için ayrılıktan parça parça olmuş bir sine” (Karaismailoğlu, 2004, s. 37) gerekir:

‘Işksuzlara benüm sözüm benzer kaya yankusına

Bir zerre '1şkı olmayan bellü bilün yabandadur (Divan 65/3).

Dertsüzlere benüm sözüm benzer kaya yankusına

Hâldaş bilür hâldaşınun gönlindeki şol râzını (Divan 359/7).

Söylenen söz ne kadar değerli olursa olsun; cahil, anlama yeteneği olmayan muhatap söylenen sözün değerini düşürür. Muhatabı iyi seçilen söz ise çok değerlidir. Assk da aşk sözü de bir emanettir ve olur olmaz yerlerde, olur olmaz kişilerle paylaşılmamalıdır:

Bî-çâre Yûnus'un altun sözini

Câhile söylemen kızıl pûl eyler (Divan 95/13).

Gevhersüz gönüllere yüz bin söz eydürisen

Hak'dan nasîb olmasa nasîb olası degül (Divan 158/3).

‘Âşıkısan miskîn Yûnus Hazret'e dutgıl yüzüni

Anlayana gevher durur söz sarrâfa satdum ahî (Divan 399/6).

Emânetdür sakıng1l 'işk haberini zinhâr

Oturup degme yirde söyleme '1şkun sözin (Divan 254/6). 


\section{Sözde aranan özellikler:}

Söz söylemek bir ihtiyaçtır; aşk ağlatır, dert söyletir:

Söylerisem sözüm savaş söylemezsem cigerüm baş

Cihân tolu durur kallâş her birinden bir taş gelür (Divan 92/3).

Yirde vü gökde 'işkıla 'ş̧kdan gelür her söz dile

Bî-çâre Yûnus ne bile ne kara okıdı ne ak (Divan130/9).

Şu didügüm keleci vücûddan taşra degül

Tefekkür kılurısan cümle sende bulasın (Divan 242/16).

Söz bağlamında önem verilen konulardan biri de "bikr-i mana"dır. Yunus bunun farkındadır ve sözün özgün olması, seçilerek söylenmesi gerektiğinin altını çizer. Ona göre anlayana bir söz yeter. Çok söz yük, öz söz ise görktür:

Bir toyı toylamak gerek bir soyı soylamak gerek

Bir sözi söylemek gerek kimse anı bilmez ola (Divan 327/6).

Yûnus bir söz söylemiş hîç bir söze benzemez

Münâfiklar elinden örter ma’nî yüzini (Divan 407/13).

Geç benlik da'vâsından söyle sözün hâsından

Ol Allah korkusindan benzi anun sarı gerek (Divan 142/2).

Bu gönüller pâsını yuyuban gidermege

Şol sözi söylegil kim sözün hülâsasıdur (Divan 29/2).

Çok söz hayvân yükidür az söz erün görkidür

Bilene bir söz yiter cânda gevher varısa (Divan 300/9). 
Sözde dedi kodu, gıybet, yalan olmamalıdır, büyükler söz taşıyanın seviyesinin domuzdan daha aşağı olduğunu nakletmişlerdir:

'Âriflerden nişân budur her gönülde hâzır ola

Kendüyi teslîm eyleye sözde kîl ü kâl olmaya (Divan 5/4).

İy dostını düşmân dutan gaybet yalan söz söyleme

Bunda gammâzlık eyleyen anda yiri tar olısar (Divan 63/2).

Bir kişinün yatlu sözin varuban kimseye dime

Biz uludan işitmişüz hınzırdan girüdür gammâz (Divan 109/5).

Sözü doğru söylemek Allah'ın bir emridir, dünyada yalan söyleyen ahirette utanacaktır.

Sözi togrı diyene kuli'l-Hak didi Çalap

Bunda yalan söyleyen yarın utanasıdur (Divan 29/3).

\section{Sonuç}

Yunus'un dil/söz hakkındaki düşüncelerine dair bu veriler, onun bu konudaki görüşleriyle ilgili olarak değerlendirme imkânı sunmaktadır. Divan'daki dil ve ilgili kavramların kullanım sıklığı, Yunus'un hemen hemen her şiirde, konuyu dil/söz meselesine getirdiği dikkati çekmektedir. Yunus'un herkesçe bilinen "söz" redifli yekaheng gazeli, bu gazel kadar olmasa da yine aynı konuya değindiği bir başka gazeli, onun dil/söz hakkındaki yaklaşımını büyük ölçüde özetlemektedir. Bunlara ilaveten Yunus her vesileyle, bu yazıda pek azına yer verdiğimiz beyitlerde, dile dair düşüncelerini dile getirmekte ve her biri belagatte, "beyân" "bedî‘ " "me‘ânî", "muktezâ-yı hâle muvâfakat ", "i'câz", "îcâz" gibi terimlerle ifade edilen konulara örnek teşkil etmektedir. 


\section{KAYNAKÇA}

İncil (Yunanca Aslından Çağdaş Türkçeye Çeviri). (1998). İstanbul: Kitabı Mukaddes Şirketi.

Karaismailoğlu, A. (2004). Mevlâna Celâleddîn Rûmî Mesnevî. I. Cilt. Ankara: Akçağ. Kur'ân-ı Kerîm (Açıklamalı Meâli). (2004). Ankara: Türkiye Diyanet Vakfı.

Tatc1, M. (2005). Yûnus Emre Divânt-Tenkitli Metin. 2. Bask1. İstanbul: Millî Eğitim Bakanlığı.

\section{Summary}

It is no coincidence that Yunus Emre is very well-known. Yet, Yunus may not have left anything else behind other than a diwan and mathnavi, but what actually carries him beyond the world he represents and makes him so well-kown is the meaning and power of his words. Indeed, his diwan is a text in which each and every reader can find answers to his/her questions.

Yunus' Diwan offers answers to questions such as "what is a language/word, which needs does it come up for, is it enough to understand eachother, how should a word be said, what is the source of a word, what are the characteristics to be looked for in the one who says a word and the one who listens to it, what is the power of a word?”.

Data provided by Yunus' Diwan as to his thoughts concerning a language/word make it possible for us to understand his views upon this issue. The frequency of the use of notions related to language in the Divan as well as the fact that Yunus deals with the concepts of language/words in almost all of his poems draws one's attention. As a matter of fact, his sensitivity regarding a language/word can be clearly seen in his "yek-aheng gazel" (single thematic gazel) with repeated words after rhymes which is known to everyone, and to a lesser extent in another "gazel" where he deals with the same subject.

In addition to these two gazels, there are many other verses of Yunus very few of which we have quoted in this article and in which Yunus expresses his approach to language. His reflections upon language are examples of subordinate fields of the science of rhetorics such as "beyân" (saying a word in an open and understandable manner) "bedî" " (saying a word/using language in a beautiful manner) "me‘ânî" (saying a word/ using language in a meaningful manner), "muktezâ-yı hâle muvâfakat" (saying a word according to a need and at the appropriate moment), 
"iccâz" (using language in such a beautiful way that it astonishes everyone), "îcâz" (speaking/writing in an eloquent manner using rhethorics). 